\title{
Efficacy and safety of tocilizumab in COVID-19 patients
}

Research Paper

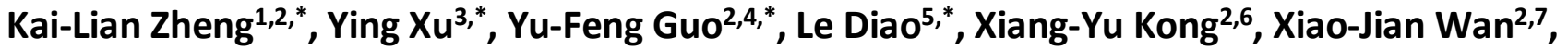 \\ Feng Zhao 2,8, Fang-Zheng Ning ${ }^{1}$, Li-Bing Wang ${ }^{2,9}$, Fan Qiao ${ }^{2,10}$, Jiang-Man Zhao5, Jia-Huan Zhou ${ }^{5}$, \\ Yue-Qian Zhong ${ }^{5}$, Shou-Xin Wu ${ }^{5}$, Yi Chen ${ }^{2,11}$, Gang Jin', Yu-Chao Dong ${ }^{2,12}$ \\ ${ }^{1}$ Department of General Surgery, Changhai Hospital, Naval Medical University, Shanghai 200433, China \\ ${ }^{2}$ Huoshenshan Hospital, Wuhan 430100, Hubei, China \\ ${ }^{3}$ Department of Gastroenterology, Hankou Hospital, Wuhan 430000, Hubei, China \\ ${ }^{4}$ Office of Medical Education, Naval Medical University, Shanghai 200433, China \\ ${ }^{5}$ Shanghai Zhangjiang Institute of Medical Innovation, Shanghai Biotecan Pharmaceuticals Co., Ltd., Shanghai \\ 201204, China \\ ${ }^{6}$ Department of Gastroenterology, Changhai Hospital, Naval Medical University, Shanghai 200433, China \\ ${ }^{7}$ Faculty of Anesthesiology, Changhai Hospital, Naval Medical University, Shanghai 200433, China \\ ${ }^{8}$ Department of Cardiovascular Medicine, Changhai Hospital, Naval Medical University, Shanghai 200433, China \\ ${ }^{9}$ Department of Hematology, Changhai Hospital, Naval Medical University, Shanghai 200433, China \\ ${ }^{10}$ Department of Cardiac Surgery, Changhai Hospital, Naval Medical University, Shanghai 200433, China \\ ${ }^{11}$ Department of infectious diseases, Changhai Hospital, Naval Medical University, Shanghai 200433, China \\ ${ }^{12}$ Respiratory and Critical Care Medicine Department, Changhai Hospital, Naval Medical University, Shanghai \\ 200433, China \\ *Equal contribution
}

Correspondence to: Yu-Chao Dong, Gang Jin, Yi Chen; email: dongyuchao2020@163.com, https://orcid.org/0000-0001-96705280; iingang@sohu.com, https://orcid.org/0000-0003-3655-2934; cheny7805@163.com, https://orcid.org/0000-0002-4377$\underline{5370}$

Keywords: COVID-19, SARS-CoV-2, tocilizumab, interleukin-6, C-reactive protein

Received: May 27, 2020

Accepted: August 14, 2020

Published: October 8, 2020

Copyright: (c) 2020 Zheng et al. This is an open access article distributed under the terms of the Creative Commons Attribution License (CC BY 3.0), which permits unrestricted use, distribution, and reproduction in any medium, provided the original author and source are credited.

\section{ABSTRACT}

In this retrospective study we assessed the efficacy and safety of tocilizumab in patients with critical or severe coronavirus disease 2019 (COVID-19). We enrolled 181 patients admitted to Huoshenshan Hospital (Wuhan, China) with confirmed COVID-19 between January 2020 and February 2020. Ninety-two patients were treated with tocilizumab, and 89 patients were treated conventionally. We analyzed the clinical manifestations, changes in CT scan images, and laboratory tests before and after tocilizumab treatment, and compared these results with the conventionally treated group. A significant reduction in the level of C-reactive protein was observed 1 week after tocilizumab administration. In some cases this meant the end of the IL-6-related cytokine storm. In addition, tocilizumab relieved fever, cough, and shortness of breath with no reported adverse drug reactions. These findings suggest tocilizumab improves clinical outcomes and is effective for treatment of patients with critical or severe COVID-19. However, future clinical trials are needed to better understand the impact of tocilizumab interference with IL- 6 and provide a therapeutic strategy for treatment of COVID-19.

\section{INTRODUCTION}

Severe acute respiratory syndrome coronavirus (SARS$\mathrm{CoV})$, Middle East respiratory syndrome-related corona- virus (MERS-CoV), and severe acute respiratory syndrome coronavirus 2 (SARS-CoV-2) are zoonotic coronaviruses that cause upper respiratory tract infections. Although SARS-CoV-2 is less deadly, it is 
more transmissible, leading to greater outbreaks [1-4]. According to the World Health Organization (WHO), at least 212 countries and regions have reported confirmed cases of coronavirus disease 2019 (COVID-19) since the first case was recorded in the city of Wuhan. This has resulted in more than 337,736 deaths worldwide as of May 24, 2020 [5]. Most patients develop pneumonia with abnormal findings on chest computed tomography (CT), which is often followed by rapid deterioration to respiratory failure [6-8]. COVID-19 is clinically manifested by fever, cough, and dyspnea leading to respiratory failure [4]. The mortality rate of severe patients is high, and the increase in severe cases puts tremendous pressure on intensive care units (ICUs) and medical staff $[6,9]$. Unfortunately, there is currently no effective treatment or antiviral medication for COVID-19 $[4,10]$.

Recent studies have shown that an increase in serum levels of proinflammatory cytokines, including interleukins (IL)-6, tumor necrosis factor $\alpha$ (TNF- $\alpha$ ), and IL12 , is associated with the pulmonary inflammation and extensive lung damage previously seen in SARS-CoV and MERS-CoV infections, and currently in COVID-19 [6, 11-14]. Earlier studies showed that patients infected with MERS, SARS-CoV, and SARS-CoV-2 exhibited high plasma levels of IL-2, IL-6, IL-10, IFN- $\gamma$, granulocyte colony-stimulating factor (G-CSF), interferon- $\gamma$-inducible protein (IP-10), and TNF- $\alpha$. This suggests that cytokine storms contribute to the severity and poor prognosis in these diseases $[4,6,14-16]$ and may be an important factor affecting COVID-19 patient mortality.

IL-6 plays a central role in acute inflammation and cytokine storms [17], and increasing evidence suggests interference with IL-6 has a potential therapeutic effect in COVID-19 [4]. Tocilizumab is a humanized anti-IL-6 receptor (IL-6R) monoclonal antibody used to treat rheumatoid arthritis. By binding to both soluble IL-6R (sIL-6R) and membrane-bound IL-6R (mIL-6R), tocilizumab inhibits IL-6 signaling [18]. The results of long-term toxicity tests on animals showed that tocilizumab is well tolerated, and no significant abnormalities were observed in other clinicopathological studies or histopathological evaluations [19-21]. In 5 phase III double-blind controlled trials, in which treatment of rheumatoid arthritis was evaluated, there were no complications or disease deterioration or death related to tocilizumab [16]. Moreover, in a recent survey of 21 critical or severe COVID-19 patients, the results showed that tocilizumab is an effective treatment for severe COVID-19 patients [4]; however, the number of patients in the survey was small, and more data are still needed. In the presents study, we assessed the clinical features, laboratory characteristics, treatment, and clinical outcomes to determine the efficacy and safety of tocilizumab in COVID-19 patients.

\section{RESULTS}

\section{Demographics and clinical characteristics}

Table 1 shows the clinical characteristics of 181 COVID19 patients, including 92 treated with tocilizumab and 89 conventionally treated patients. The mean ages of the tocilizumab and conventionally treated patients were 68.8 (range, 25-87) and 66.8 (range, 25-85) years, respectively. Among those receiving tocilizumab, 65 (70.7\%) had at least one coexisting disorder (i.e., hypertension, diabetes, cardiovascular and/or cerebrovascular disease, cancer, or liver cirrhosis), whereas only 25 (28.1\%) conventionally treated patients had a coexisting disorder $(\mathrm{P}<0.0001)$. Among tocilizumab treated patients, $84.8 \%$ had critical or severe disease before tocilizumab, whereas only $46.1 \%$ of those receiving conventional treatment were critical or severe $(\mathrm{P}<0.0001)$. Conventionally treated patients had significantly fewer hospitalization days than the tocilizumab group (mean, 16.4 vs. 27.5, $\mathrm{P}<0.0001$ ). A total of $83(90.2 \%)$ patients receiving tocilizumab and 88 (98.9\%) conventionally treated patients were discharged from the hospital. Nine patients in the tocilizumab-treated patients died, whereas only 1 conventionally treated patient died. There were no significant differences in age, sex distribution, and negative-conversing days between the two groups.

Although fever, cough, shortness of breath, and fatigue were the initial symptoms of most patients, some patients developed chest distress, myalgia, and rhinorrhea. Atypical symptoms, such as diarrhea and headache, were less common and may have been associated with central nervous system [22] and digestive system invasion by SARS-CoV-2. After 1-3 days of tocilizumab treatment, a large portion of the COVID-19 patients showed clinical remission of their symptom (Table 2). We performed a logistic regression analysis to investigate whether COVID-19 severity and coexisting disorders of patients could affect the response to treatment. The results showed the critical patients were at a higher risk $(\mathrm{OR}=7.000, \mathrm{P}=0.001)$ of showing no improvement in their cough than moderate and severe patients (Table 2). But it appears that the severity of the disease and coexisting diseases had no significant effect on other clinical symptoms.

\section{Laboratory indices}

Table 3 summarizes the laboratory indices of 181 patients. After tocilizumab treatment, white blood cell counts, C-reactive protein (CRP) levels, maximum 
Table 1. Clinical characteristics of 181 patients with COVID-19 caused by SARS-CoV-2, according to disease severity.

\begin{tabular}{lccc}
\hline $\begin{array}{l}\text { Clinical characteristics } \\
\text { Mean (range) }\end{array}$ & $\begin{array}{c}\text { Tocilizumab treatment } \\
(\mathbf{n = 9 2})\end{array}$ & $\begin{array}{c}\text { Conventional treatment } \\
(\mathbf{n = 8 9})\end{array}$ & $\mathbf{P}$ \\
\hline Age, mean (range), years & $68.8(25-87)$ & $66.8(25-85)$ & 0.258 \\
Gender & & & 0.213 \\
$\quad$ Male & $57 / 92(62.0 \%)$ & $47 / 89(52.8 \%)$ & \\
$\quad$ Female & $35 / 92(38.0 \%)$ & $42 / 89(47.2 \%)$ & 0.001 \\
$\quad$ Coexisting disorders & $65 / 92(70.7 \%)$ & $25 / 89(28.1 \%)$ & 0.001 \\
State of illness & & & \\
$\quad$ Critical or severe & $78 / 92(84.8 \%)$ & $41 / 89(46.1 \%)$ & 0.001 \\
$\quad$ Moderate & $14 / 92(15.2 \%)$ & $48 / 89(53.9 \%)$ & 0.018 \\
$\quad$ Hospitalization days (range) - days & $27.5(6-62)$ & $16.4(4-46)$ & \\
Clinical outcome & & & 0.184 \\
$\quad$ Discharge from hospital & $83 / 92(90.2 \%)$ & $88 / 89(98.9 \%)$ & $1 / 89(1.1 \%)$ \\
$\quad$ Dead & $9 / 92(9.8 \%)$ & $18.8(1-57)$ & \\
$\quad$ Negative-conversing, mean (range), days & $22.4(1-57)$ & & \\
& & & \\
\hline
\end{tabular}

Table 2. Clinical symptoms and influence on non-improvement of symptoms after tocilizumab treatment by COVID19 severity and coexisting disorders.

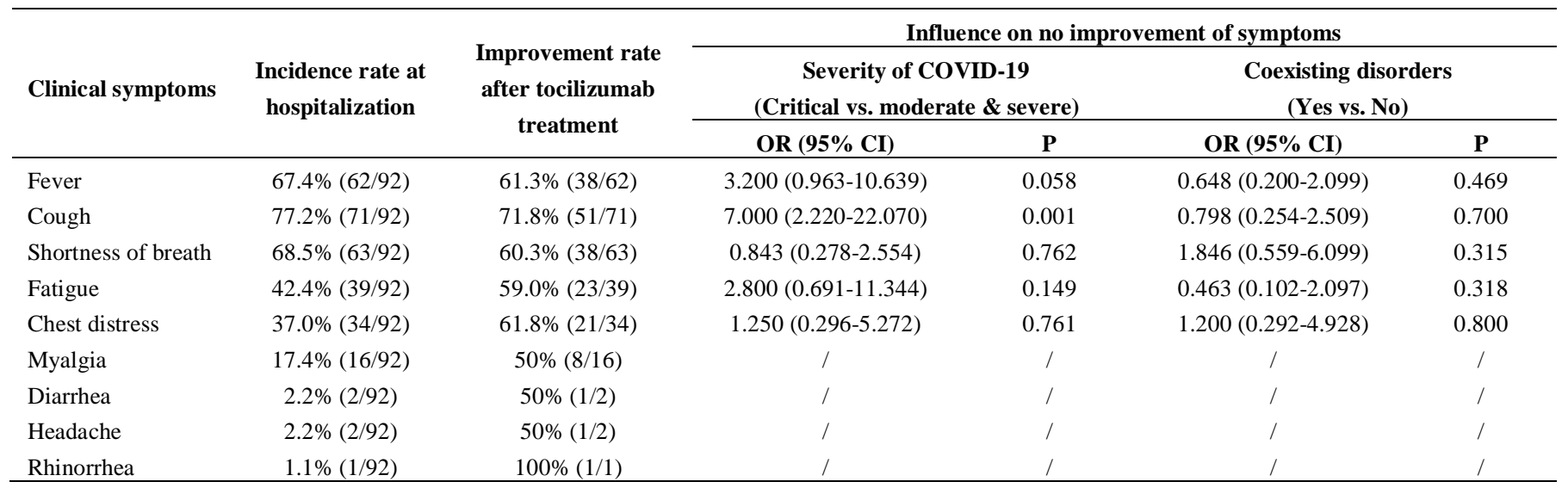

temperature, minimum oxygen saturation, highest respiratory rate, and maximum heart rate were all significantly improved $(\mathrm{P}<0.0001, \mathrm{P}<0.0001, \mathrm{P}<0.0001$, $\mathrm{P}<0.0001, \mathrm{P}=0.0011, \mathrm{P}<0.0001$, respectively), and the mean values were close to normal. Before treatment, CRP levels were higher in tocilizumab-treated than conventionally treated patients $(50.8 \pm 67.3 \mathrm{mg} / \mathrm{L}$ vs. $23.0 \pm 28.7 \mathrm{mg} / \mathrm{L}$ ) (Table 3). The mean IL-6 level before tocilizumab was $102.1 \pm 535.1 \mathrm{pg} / \mathrm{mL}$, indicating that IL-6 was upregulated in these COVID-19 patients. Notably, after 1 week of tocilizumab treatment, IL-6 levels in these patients' had increased to $369.7 \pm 778.6 \mathrm{pg} / \mathrm{mL} \quad(\mathrm{P}<$ 0.0001). In sharp contrast, the mean IL-6 level before conventional treatment was only $29.2 \pm 71.6 \mathrm{pg} / \mathrm{mL}$.

\section{Imaging features}

All patients had abnormal chest CT on presentation before tocilizumab treatment. The primary abnormalities on the initial chest CT were plaque-like, ground-glass opacities and focal consolidation. However, after 1 week of tocilizumab treatment, most CT scans showed significant remission.

\section{Clinical presentations}

We evaluated the effects of tocilizumab treatment 1 week after treatment. We found that 72 patients showed improvement, 10 patients showed no improvement, and 9 critical patients had died. We also evaluated the effects of conventional treatment within 2 weeks of hospitalization. We found that 79 patients had improved, 9 patients showed no improvement, and 1 critical patient had died. In that patient, IL-6 level suddenly rose from $529.5 \mathrm{pg} / \mathrm{mL}$ to $5000 \mathrm{pg} / \mathrm{mL}$ before his death. This result suggests that in critical and severe patients, IL-6 levels may determine the prognosis and overall mortality of COVID-19 patients. We therefore focused our investigation on factors affecting earlystage clinical outcomes of severe patients. 
Table 3. Comparison of laboratory findings between tocilizumab and conventional treatment.

\begin{tabular}{|c|c|c|c|c|c|c|c|}
\hline \multirow{2}{*}{$\begin{array}{l}\text { Laboratory findings mean } \\
\text { mean } \pm \text { SD }\end{array}$} & & \multicolumn{3}{|c|}{ Tocilizumab treatment } & \multicolumn{3}{|c|}{ Conventional treatment } \\
\hline & & $\begin{array}{c}\text { Before the } \\
\text { tocilizumab }\end{array}$ & $\begin{array}{c}\text { One week after tocilizumab } \\
\text { treatment }\end{array}$ & $\mathbf{P}$ & $\begin{array}{c}\begin{array}{c}\text { Prior to } \\
\text { admission }\end{array} \\
\end{array}$ & $\begin{array}{l}\text { One week after } \\
\text { hospitalization }\end{array}$ & $P$ value \\
\hline \multirow[t]{3}{*}{ White-cell count, $\times 10^{9} / \mathrm{L}$} & & $7.6 \pm 3.7$ & $6.6 \pm 5.7$ & $<0.0001$ & $7.2 \pm 3.9$ & $7.0 \pm 3.8$ & 0.571 \\
\hline & $<4 * 10^{\wedge} 9 / \mathrm{L}$ & $7 / 92$ & $19 / 92$ & & $11 / 89$ & $3 / 89$ & \\
\hline & $>10^{*} 10^{\wedge} 9 / \mathrm{L}$ & $19 / 92$ & $7 / 92$ & & $8 / 89$ & $6 / 89$ & \\
\hline \multirow[t]{2}{*}{$\begin{array}{l}\text { Absolute lymphocyte, } \\
\times 10^{9} / \mathrm{L}\end{array}$} & & $1.4 \pm 3.3$ & $1.3 \pm 0.6$ & 0.1754 & $1.4 \pm 0.6$ & $1.5 \pm 0.7$ & 0.008 \\
\hline & $<1.1 * 10^{\wedge} 9 / \mathrm{L}$ & $43 / 92$ & $29 / 92$ & & $36 / 89$ & $15 / 89$ & \\
\hline \multirow[t]{2}{*}{ C-reactive protein, $\mathrm{mg} / \mathrm{L}$} & & $50.8 \pm 67.3$ & $7.0 \pm 22.2$ & $<0.0001$ & $23.0 \pm 28.7$ & $21.0 \pm 34.7$ & 0.428 \\
\hline & $>7 \mathrm{mg} / \mathrm{L}$ & $70 / 92$ & $14 / 92$ & & $51 / 89$ & $31 / 89$ & \\
\hline \multirow[t]{2}{*}{ Procalcitonin, ng/ml } & & $0.5 \pm 2.5$ & $0.2 \pm 0.5$ & 0.0216 & $0.4 \pm 1.8$ & $0.1 \pm 0.2$ & 0.326 \\
\hline & $>0.05 \mathrm{ng} / \mathrm{mL}$ & $52 / 92$ & $21 / 92$ & & $36 / 89$ & $17 / 89$ & \\
\hline \multirow[t]{2}{*}{ Interleukin-6, pg/mL } & & $102.1 \pm 535.1$ & $369.7 \pm 778.6$ & $<0.0001$ & $29.2 \pm 71.6$ & $29.4 \pm 81$ & 0.219 \\
\hline & $>7 \mathrm{pg} / \mathrm{mL}$ & $86 / 92$ & $91 / 92$ & & $76 / 89$ & $69 / 89$ & \\
\hline Maximum temperature, ${ }^{\circ} \mathrm{C}$ & & $37.4 \pm 0.7$ & $36.9 \pm 0.4$ & $<0.0001$ & $36.7 \pm 0.6$ & $37.1 \pm 0.4$ & $<0.0001$ \\
\hline $\begin{array}{l}\text { Minimum oxygen } \\
\text { saturation, } \%\end{array}$ & & $90.3 \pm 8.0$ & $93.1 \pm 9.9$ & $<0.0001$ & $96.0 \pm 2.9$ & $94.1 \pm 4.8$ & $<0.0001$ \\
\hline \multirow[t]{2}{*}{ Neutrophils, $\times 10^{9} / \mathrm{L}$} & & $5.7 \pm 3.4$ & $4.4 \pm 5.4$ & $<0.0001$ & $4.8 \pm 3.3$ & $4.7 \pm 3.6$ & 0.265 \\
\hline & $>6.3 * 10^{\wedge} 9 / \mathrm{L}$ & $34 / 92$ & $11 / 92$ & & $16 / 89$ & $11 / 89$ & \\
\hline \multirow[t]{2}{*}{ Total bilirubin, umol/L } & & $11.9 \pm 6.4$ & $10.8 \pm 10.1$ & 0.0026 & $11.6 \pm 12.9$ & $12.6 \pm 19.9$ & 0.847 \\
\hline & $>20.5 \mathrm{umol} / \mathrm{L}$ & 9/92 & $7 / 92$ & & $5 / 89$ & $4 / 89$ & \\
\hline Direct bilirubin, umol/L & & $5.0 \pm 3.1$ & $4.1 \pm 4.7$ & 0.0006 & $5 \pm 8.2$ & $5.6 \pm 11.9$ & 0.914 \\
\hline Highest respiratory rate & & $29.2 \pm 14.4$ & $26.2 \pm 19.7$ & 0.0011 & $20.3 \pm 2.5$ & $22.3 \pm 2.1$ & $<0.0001$ \\
\hline Maximum heart rate & & $109 \pm 21.1$ & $95.5 \pm 14.9$ & $<0.0001$ & $92.1 \pm 14.8$ & $102.8 \pm 15.6$ & $<0.0001$ \\
\hline \multirow[t]{2}{*}{ Platelet count, $* 10^{\wedge} 9 / \mathrm{L}$} & & $220 \pm 86.9$ & $219.2 \pm 83$ & 0.5118 & $228.3 \pm 96$ & $246.5 \pm 91$ & 0.100 \\
\hline & $<125^{*} 10^{\wedge} 9 / \mathrm{L}$ & $14 / 92$ & $5 / 92$ & & $10 / 89$ & $6 / 89$ & \\
\hline Mean platelet volume & & $10.3 \pm 1.2$ & $9.9 \pm 1.1$ & 0.0730 & $10.1 \pm 1.2$ & $9.9 \pm 1.1$ & 0.078 \\
\hline \multirow[t]{2}{*}{ Total protein, g/L } & & $61.0 \pm 6.9$ & $62.4 \pm 7.1$ & 0.2706 & $65.3 \pm 7.1$ & $64.2 \pm 9.6$ & 0.881 \\
\hline & $<60 \mathrm{~g} / \mathrm{L}$ & $46 / 92$ & $28 / 92$ & & $20 / 89$ & $16 / 89$ & \\
\hline \multirow[t]{2}{*}{ Albumin, g/L } & & $33.0 \pm 4.7$ & $35.4 \pm 4$ & 0.0009 & $36 \pm 4.1$ & $35.8 \pm 4.7$ & 0.537 \\
\hline & $<34 \mathrm{~g} / \mathrm{L}$ & $54 / 92$ & $28 / 92$ & & $23 / 89$ & $28 / 92$ & \\
\hline Alanine aminotransferase & & $35.3 \pm 29.6$ & $47.6 \pm 87.9$ & 0.5240 & $27.1 \pm 26.6$ & $30 \pm 29.9$ & 0.499 \\
\hline Aspartate aminotransferase & & $26.6 \pm 14.3$ & $35.3 \pm 57.9$ & 0.3393 & $29.9 \pm 44.3$ & $27.5 \pm 25.4$ & 0.361 \\
\hline Ratio of albumin to globulin & & $1.2 \pm 0.2$ & $1.3 \pm 0.3$ & 0.0177 & $1.2 \pm 0.2$ & $1.2 \pm 0.2$ & 0.739 \\
\hline Lactate dehydrogenase & & $261.9 \pm 111.3$ & $241.1 \pm 82.3$ & 0.3729 & $205.4 \pm 83.5$ & $197.4 \pm 47.7$ & 0.079 \\
\hline $\begin{array}{l}\text { Carbon dioxide combining } \\
\text { power }\end{array}$ & & $23.8 \pm 3.3$ & $24.7 \pm 2.8$ & 0.077 & $24.3 \pm 2.5$ & $27.5 \pm 20$ & 0.214 \\
\hline Creatinine, umol/L & & $78.5 \pm 41.9$ & $75.9 \pm 36.7$ & 0.888 & $70 \pm 28.4$ & $68.6 \pm 25.8$ & 0.001 \\
\hline $\begin{array}{l}\text { Blood urea nitrogen, } \\
\mathrm{mmol} / \mathrm{L}\end{array}$ & & $6.2 \pm 3.7$ & $10.4 \pm 34.1$ & 0.8074 & $5.5 \pm 2.9$ & $6 \pm 2.7$ & 0.992 \\
\hline Sodium, mmol/L & & $138.1 \pm 14$ & $140 \pm 3.3$ & 0.2887 & $141.5 \pm 4.7$ & $140.9 \pm 3.8$ & 0.291 \\
\hline Potassium, mmol/L & & $4.2 \pm 0.5$ & $4.4 \pm 0.4$ & 0.2087 & $4.1 \pm 0.5$ & $4.2 \pm 0.5$ & 0.476 \\
\hline Calcium, mmol/L & & $2.0 \pm 0.1$ & $2.1 \pm 0.1$ & $<0.0001$ & $2.1 \pm 0.1$ & $2.2 \pm 0.1$ & 0.054 \\
\hline $\begin{array}{l}\text { Hypersensitive troponin, } \\
\mathrm{ng} / \mathrm{L}\end{array}$ & & $0.1 \pm 0.3$ & $0.03 \pm 0.08$ & 0.3792 & $0 \pm 0.2$ & $0 \pm 0.1$ & 0.203 \\
\hline Fibrinogen, g/L & & $3.7 \pm 1.3$ & $2.5 \pm 0.7$ & $<0.0001$ & $3.4 \pm 0.7$ & $3.6 \pm 2.1$ & 0.437 \\
\hline D-dimer, mg/L & & $2.5 \pm 3.3$ & $2.9 \pm 3.7$ & 0.1929 & $1.3 \pm 1.6$ & $1.4 \pm 1.2$ & 0.069 \\
\hline
\end{tabular}




\section{Treatment}

Immediately before and within 2 weeks after hospitalization, IL-6 levels in the 89 conventionally treated patients exhibited little change (mean, 29.2 \pm 71.6 $\mathrm{pg} / \mathrm{mL}$ vs. $29.4 \pm 81 \mathrm{pg} / \mathrm{mL}, \mathrm{P}=0.219$ ). In sharp contrast, after 3 days of treatment, IL-6 levels in the 92 tocilizumab-treated patients had increased significantly $(102.1 \pm 535.1 \mathrm{pg} / \mathrm{mL}$ vs. $337.7 \pm 723.8 \mathrm{pg} / \mathrm{mL}, \quad \mathrm{P}<$ $0.0001)$, while white blood cell counts had significantly decreased $\left(7.6 \pm 3.7 \times 10^{9} / \mathrm{L}\right.$ vs. $6.6 \pm 5.7 \times 10^{9} / \mathrm{L}, \mathrm{P}<$ 0.0001). In addition, CRP levels were significantly lower 1 week after tocilizumab treatment $(50.8 \pm 67.3$ $\mathrm{mg} / \mathrm{L}$ vs. $7.0 \pm 22.2 \mathrm{mg} / \mathrm{L}, \mathrm{P}<0.0001$ ) (Table 3 ).

Three days after tocilizumab treatment, the body temperature of most patients had dropped, gradually moving closer to the normal range (Figure 1A). Simultaneously, the clinical symptoms were greatly attenuated over the following days. Figure 1B shows that 1 week after tocilizumab treatment, the CRP levels had decreased significantly in all but one patient. In that patient, who was critical, CRP levels greatly increased, and the patient died after 27 days in the hospital. Intriguingly, IL-6 levels increased significantly in tocilizumab-treated patients, though their condition was significantly improved (Figure 1C). No adverse drug reactions were reported during the tocilizumab treatment.

\section{Risk factors for poor clinical outcomes in critical COVID-19 patients}

Univariate logistic regression analysis showed that high maximum temperature $(\mathrm{OR}=5.205$ [95\% CI, 1.16023.358], $\mathrm{P}=0.031)$, maximum heart rate $(\mathrm{OR}=1.088$ [95\% CI, 1.010-1.171], $\mathrm{P}=0.026)$, and lactate dehydrogenase levels $(\mathrm{OR}=1.023$ [95\% CI, 1.0041.043], $\mathrm{P}=0.018$ ) were risk factors for poor clinical outcomes among critical patients before tocilizumab treatment. In addition, maximum heart rate $(\mathrm{OR}=1.169$ [95\% CI, 1.007-1.357], $\mathrm{P}=0.041)$, white blood cell count $(\mathrm{OR}=1.503$ [95\% CI, 1.029-2.196], $\mathrm{P}=0.035)$, mean platelet volume $(\mathrm{OR}=2.902$ [95\% CI, 1.0408.100], $\mathrm{P}=0.042)$, blood urea nitrogen $(\mathrm{OR}=1.426[95 \%$ $\mathrm{CI}$, 1.048-1.941], $\mathrm{P}=0.024)$, sodium $(\mathrm{OR}=1.488$ [95\% CI, 1.027-2.158], $\mathrm{P}=0.036)$, and $\mathrm{CRP}(\mathrm{OR}=1.082$ [95\% CI, 1.003-1.168], $\mathrm{P}=0.041$ ) were all risk factors for poor clinical outcomes among critical patients 1 to 3 days after tocilizumab treatment. High minimum oxygen saturation $(\mathrm{OR}=0.704$ [95\% CI, 0.498-0.995], $\mathrm{P}=0.047)$ and high platelet count $(\mathrm{OR}=0.979$ [95\% CI, 0.9580.999], $\mathrm{P}=0.042$ ) were identified as protective factors against poor clinical outcomes among severe patients. Conversely, reduced platelet count was a risk factor for poor clinical outcomes (Table 4).

\section{DISCUSSION}

SARS-CoV-2, the virus that causes COVID-19, as well as SARS-CoV and MERS-CoV belong to genus $\beta$ and infect the lower respiratory tract, causing severe respiratory syndrome in humans $[23,24]$. On May 25, 2020, the Chinese Center for Disease Control and Prevention reported 84,536 confirmed COVID-19 cases and 4,645 related. Thus COVID-19 had caused more deaths than severe acute respiratory syndrome (SARS) or MERS [25].

In this retrospective study, we observed a cohort of 181 COVID-19 patients with laboratory-confirmed SARSCoV-2 infections. This included 92 patients treated with tocilizumab and 89 treated conventionally. In a survey of 21 critical or severe COVID-19 patients, the clinical data showed that, in most patients, respiratory symptoms, hypoxemia, and CT opacity changes improved immediately after tocilizumab treatment, which suggests tocilizumab may be a efficacious treatment for COVID-19 [4]. In the present study, analysis of the tocilizumab-treated patients yielded similar results. However, after comparison with the outcomes of the conventionally treated patients, we believe that the patient's own immunity, disease severity, and comprehensive treatment are directly related to the outcomes with these patients. They cannot be attributed solely to tocilizumab treatment. Nonetheless, it is undeniable that tocilizumab, an IL-6 blocker, played an important role in alleviating cytokine storms, which can significantly improve the clinical symptoms and laboratory findings of critical and severe patients.

Consistent with earlier reports [4], no adverse drug reactions or subsequent pulmonary infection were reported with tocilizumab treatment. The observation of dynamic IL-6 levels also helps to confirm the COVID19 response to treatment [26]. Consistent with earlier observations [26], we found that IL-6 levels spiked after tocilizumab treatment. This is likely because IL-6 is mainly eliminated via IL-6R-mediated clearance [27], and the binding of tocilizumab to IL-6R inhibits receptor-mediated IL- 6 clearance [26]. Primarily synthesized by liver hepatocytes and secreted in plasma, CRP is regulated mainly by IL-6 [28]. In our study, CRP levels were elevated in $76.1 \%$ of patients (70/92) before receiving tocilizumab, but this was reduced to $15.2 \%$ (14/92) 1 week after tocilizumab treatment, indicating the patient's inflammation was alleviated. Correspondingly, the patients' clinical symptoms also significantly improved after tocilizumab. It therefore appears that tocilizumab can be used to effectively treat patients with COVID-19, and that its beneficial effects are related to its ability to suppress IL-6-related febrile 

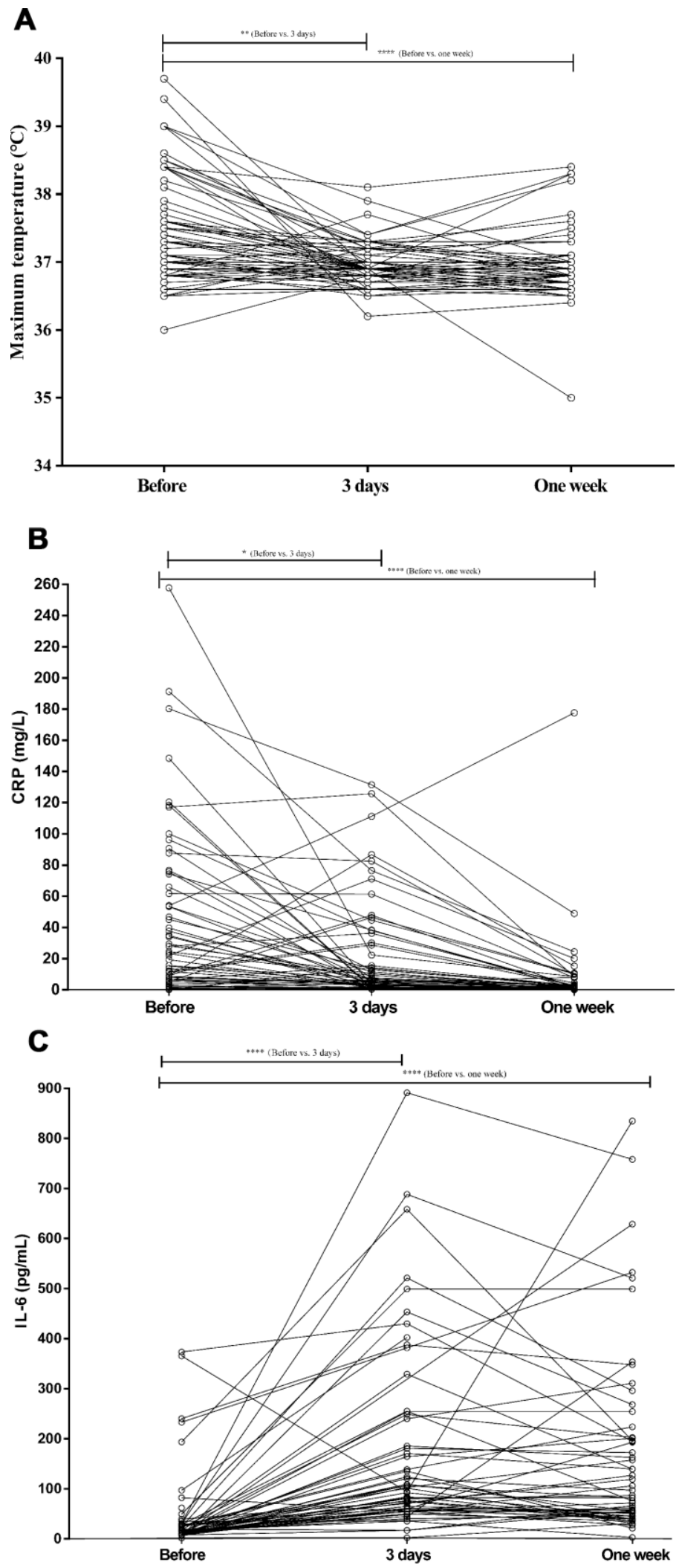

Figure 1. The values of maximum temperature, CRP, and IL-6 levels before and after tocilizumab treatment in COVID-19 patients. (A) The fever returned toward normal in most patients treated conventionally or with tocilizumab. (B) CRP levels decreased significantly after tocilizumab treatment and returned to normal in most conventionally treated patients. (C) IL-6 increased significantly after tocilizumab treatment in most patients. 
Table 4 Univariate logistic regression analysis to investigate risk factors for poor diagnosis of critical COVID-19 patients.

\begin{tabular}{lcc}
\hline Variables & OR $(\mathbf{9 5 \%} \mathbf{C I})$ & P \\
\hline Before treatment & & \\
Maximum temperature, ${ }^{\circ} \mathrm{C}$ & $5.205(1.160-23.358)$ & 0.031 \\
Maximum heart rate & $1.088(1.010-1.171)$ & 0.026 \\
Lactate dehydrogenase & $1.023(1.004-1.043)$ & 0.018 \\
$\mathbf{1 - 3}$ days after tocilizumab treatment & & \\
Minimum oxygen saturation, $\%$ & $0.704(0.498-0.995)$ & 0.047 \\
Maximum heart rate & $1.169(1.007-1.357)$ & 0.041 \\
White-cell count, $\times 10^{\wedge} 9 / \mathrm{L}$ & $1.503(1.029-2.196)$ & 0.035 \\
Platelet count, $* 10^{\wedge} 9 / \mathrm{L}$ & $0.979(0.958-0.999)$ & 0.042 \\
Mean platelet volume, $\mathrm{fL}$ & $2.902(1.040-8.100)$ & 0.042 \\
Blood urea nitrogen, $\mathrm{mmol} / \mathrm{L}$ & $1.426(1.048-1.941)$ & 0.024 \\
Sodium, mmol/L & $1.488(1.027-2.158)$ & 0.036 \\
C-reactive protein, $\mathrm{mg} / \mathrm{L}$ & $1.082(1.003-1.168)$ & 0.041 \\
\hline
\end{tabular}

and inflammatory storm responses [4]. In addition, we observed the IL-6 levels in some patients were trending downward 1 week after tocilizumab treatment, which may also reflect the inhibitory effect of tocilizumab on inflammatory activity and the resultant improvement in the patients' clinical status.

As a virus spreads within a host, the host's immune response is activated, and an environment of cytokines is established, which can lead to clearance of the virus and cure for the patient [29]. However, when cytokines increase past a threshold level, they can trigger a cytokine storm, which can severely damage multiple organs and lead to multiple organ dysfunction syndrome or death $[9,29-31]$. In the treatment of severe and critical COVID-19 patients, the balance between immune activation and inflammation inhibition is crucial. The latest research shows that any preventive intervention that reduces inflammation may have a negative effect on viral clearance [29]. In the present study, there was no significant difference in negativeconversing days between tocilizumab-treated and conventionally treated patients ( 22.4 vs. $18.8, \mathrm{P}=0.184)$. The dose and frequency of tocilizumab administration were in accordance with Chinese management guidelines for COVID-19 (version 7.0) [32]. Most patients with COVID-19 were administered the drug only once, and the total amount did not exceed $400 \mathrm{mg}$. Based on our findings, we believe the appropriate amount of tocilizumab to reduce inflammation is beneficial, and does not affect the number of negativeconversing days in COVID-19 patients. This suggests the appropriate level of tocilizumab treatment may not negatively affect viral clearance. However, more clinical research on IL- 6 and other cytokines is needed to determine the proper balance between immune activation and inflammation inhibition.
Our univariate and multivariate regression analyses showed maximum temperature to be an independent risk factor for poor clinical outcomes of critical patients before tocilizumab treatment. Then 1-3 days of after tocilizumab treatment, mean platelet volume and CRP were identified as independent risk factors for poor clinical outcomes among critical patients. Mean platelet volume is an indicator of inflammation in patients with various diseases [33-35]. Cytokine storms mediated by overproduction of proinflammatory cytokines is an important factor leading to high mortality in COVID-19 patients and may be a key reason for their poor prognosis. CRP is a nonspecific acute-phase protein induced by IL-6 and a sensitive biomarker of inflammation and infection [36]. During acute inflammatory responses, CRP expression rapidly increases [37, 38]. Recent research showed that the serum CRP levels can be used to effectively assess disease severity in COVID19 patients [39]. Therefore, an increase in CRP may also be a sign of poor patient prognosis.

This study has several limitations, including the small number of patients, the need to enhance the evidence strength, and missing viral load data. Additionally, other cytokines, including IL-2, IL-10, and TNF- $\alpha$, should also be considered.

Under its medication guidelines, tocilizumab can effectively improve clinical symptoms and slow the deterioration of COVID-19 patients. However, directly related to any patient's prognosis is also the immunity of the patient, the severity of the disease, and the comprehensive treatment. Although these preliminary results look promising, more evidence and high-quality clinical trials are required to understand the efficacy of tocilizumab in COVID-19. And of course the 
development of vaccines will be the most effective way to prevent COVID-19.

\section{MATERIALS AND METHODS}

\section{Study population}

This single-center, retrospective observational study recruited 181 patients admitted to Huoshenshan Hospital (Wuhan, China) with confirmed COVID-19 between January 2020 and February 2020. Ninety-two patients were treated with tocilizumab, and 89 patients were treated with conventional treatment. All patients were diagnosed with COVID-19 based on World Health Organization interim guidance, and were clinically classified based on the Chinese management guidelines for COVID-19 (version 7.0) [32]. Moderate patients were defined as those with fever, respiratory symptoms and imaging evidence of pneumonia. Patients who met any of the following criteria were defined as severe: 1 ) tachypnoea ( $\leq 30$ breaths/ $\mathrm{min}$ ), 2) oxygen saturation $\leq 93 \%$ at rest, 3) $\mathrm{PaO}_{2} / \mathrm{FIO}_{2}<300$ $\mathrm{mmHg}(1 \mathrm{~mm} \mathrm{Hg}=0.133 \mathrm{kPa})$, and 4) progression of the lesion by $>50 \%$ within $24-38$ hours based on pulmonary imaging. Critical patients were defined as those with one or more of the following criteria: 1) respiratory failure, 2) septic shock, or 3) multiple organ dysfunction and/or failure.

According to the Chinese management guideline for COVID-19 (version 7.0) [32], the standard ages for patients who can be treated with tocilizumab are between 18 and 85 years. In addition, these patients must exhibit elevated IL-6 levels and multiple lung lesions showing significant progression of $>50 \%$ within 24-38 hours on pulmonary imaging. The first dose of tocilizumab was $4-8 \mathrm{mg} / \mathrm{kg}$. The recommended dose is $400 \mathrm{mg}$. A total of $100 \mathrm{ml}$ of saline was added, and the infusion time was more than 1 hour. For patients presenting with fever, an additional dose (same dose as before) was administered if there was still fever after 24 hours. The interval between the two administrations was always $\geq 12$ hours, and the cumulative number of doses was never more than 2 . The maximum single dose never exceeded $800 \mathrm{mg}$.

Tocilizumab was contraindicated for pregnant or lactating women; patients with ALT/AST >5 times ULN, neutrophils $<0.5 \times 10^{9} / \mathrm{L}$, platelets less than $50 \times 10^{9} / \mathrm{L}$; patients diagnosed of rheumatic immunerelated disease; patients on long-term oral anti-rejection drugs or immunomodulatory drugs; patients hypersensitive to tocilizumab or any excipients; patients with active tuberculosis, hepatitis, and definite bacterial and fungal infections; organ transplant patients; and patients with mental disorders. IL-6 levels were measured using FACS or electrochemical luminescence methods (Roche Diagnostics GmbH). The normal range of IL-6 was $<7 \mathrm{pg} / \mathrm{mL}$.

The study was approved by Medical Research Ethics Committee of the Huoshenshan Hospital (Approval number: hssll033). All patients provided informed consent before treatment and agreed to publication of this case series. We are committed to protecting patient privacy and complying with the Helsinki Declaration.

\section{Procedure}

Demographic, clinical, laboratory, and treatment data were collected from electronic medical records. All data were checked by two physicians. The personal and clinical data collected included sex, age, medical history, and initial symptoms, including fever, cough, shortness of breath, fatigue, chest distress, myalgia, diarrhea, headache, and rhinorrhea. Real-time reverse transcriptasepolymerase chain reaction assays were used to detect SARS-CoV-2 infection. In addition, patients underwent an initial examination and then complete blood counts (white blood cells, neutrophils, lymphocytes, and platelets), serum biochemical tests (renal and liver function, carbon dioxide combining power, creatinine, and electrolytes), coagulation profile, procalcitonin, CRP, and myocardial enzymes 1-3 days and 1 week after tocilizumab. The patients' follow-up endpoint was discharge or death. CT scans were used to image the lungs of all patients. The effect of treatment on COVID-19 patients after hospitalization for 1 week was evaluated based on Chinese management guidelines for COVID-19 (version 7.0) [32], as described previously.

\section{Statistical analysis}

Statistical analyses were performed using SPSS 19.0 (IBM, NY, USA) and R 3.5.1 software. Continuous variables are presented as the mean (range) or mean \pm $\mathrm{SD}$. If continuous variables conformed to a normal distribution, unpaired t-tests were used to analyze differences. Otherwise, the Mann-Whitney U test was used. When comparing datasets containing multiple groups, one-way analysis of variance was used for normally distributed datasets, and the Kruskal-Wallis test was used for datasets not normally distributed. Categorical variables were summarized as the counts and percentages, and analyzed using the $\chi^{2}$ test or Fisher's exact test, as appropriate. Univariate logistic regression analyses were performed to identify risk factors for disease progression. A two- of $\mathrm{P}<0.05$ were considered statistically significant. sided values 


\section{AUTHOR CONTRIBUTIONS}

YCD, GJ, YC conceived and designed the study. KLZ, YX, YFG, XYK, XJW, FZ, FZN, LBW, FQ, and YCD acquired the data. LD, KLZ, JMZ, JHZ, and SXW analyzed and interpreted the data. KLZ, LD, JMZ, and YQZ drafted the article. YCD approved final version of the manuscript.

\section{CONFLICTS OF INTEREST}

All authors report no conflicts of interest related to the submitted work.

\section{FUNDING}

This work was supported by Shanghai Natural Science Foundation [Grant No.19ZR1455800].

\section{REFERENCES}

1. Haagmans BL, Al Dhahiry SH, Reusken CB, Raj VS, Galiano M, Myers R, Godeke GJ, Jonges M, Farag E, Diab A, Ghobashy H, Alhajri F, Al-Thani M, et al. Middle east respiratory syndrome coronavirus in dromedary camels: an outbreak investigation. Lancet Infect Dis. 2014; 14:140-45.

https://doi.org/10.1016/S1473-3099(13)70690-X

PMID:24355866

2. Hu B, Zeng LP, Yang XL, Ge XY, Zhang W, Li B, Xie JZ, Shen XR, Zhang YZ, Wang N, Luo DS, Zheng XS, Wang $\mathrm{MN}$, et al. Discovery of a rich gene pool of bat SARSrelated coronaviruses provides new insights into the origin of SARS coronavirus. PLoS Pathog. 2017; 13:e1006698.

https://doi.org/10.1371/journal.ppat.1006698

PMID:29190287

3. Song HD, Tu CC, Zhang GW, Wang SY, Zheng K, Lei LC, Chen QX, Gao YW, Zhou HQ, Xiang H, Zheng HJ, Chern SW, Cheng F, et al. Cross-host evolution of severe acute respiratory syndrome coronavirus in palm civet and human. Proc Natl Acad Sci USA. 2005; 102:2430-35.

https://doi.org/10.1073/pnas.0409608102 PMID:15695582

4. Xu X, Han $M$, Li T, Sun $W$, Wang $D$, Fu B, Zhou $Y$, Zheng X, Yang Y, Li X, Zhang X, Pan A, Wei H. Effective treatment of severe COVID-19 patients with tocilizumab. Proc Natl Acad Sci USA. 2020; 117:10970-75.

https://doi.org/10.1073/pnas.2005615117

PMID:32350134

5. Organization, W.H., Report of the WHO-China Joint Mission on Coronavirus Disease 2019 (COVID-19).
6. Huang $C$, Wang $Y$, Li X, Ren L, Zhao J, Hu Y, Zhang L, Fan G, Xu J, Gu X, Cheng Z, Yu T, Xia J, et al. Clinical features of patients infected with 2019 novel coronavirus in Wuhan, China. Lancet. 2020; 395:497-506. https://doi.org/10.1016/S0140-6736(20)30183-5 PMID:31986264

7. Wang $D, H u B, H u ~ C$, Zhu F, Liu X, Zhang J, Wang B, Xiang $\mathrm{H}$, Cheng $\mathrm{Z}$, Xiong $\mathrm{Y}$, Zhao $\mathrm{Y}$, Li Y, Wang $\mathrm{X}$, Peng Z. Clinical characteristics of 138 hospitalized patients with 2019 novel coronavirus-infected pneumonia in Wuhan, China. JAMA. 2020; 323:1061-69. https://doi.org/10.1001/jama.2020.1585 PMID: $\underline{32031570}$

8. Bennardo F, Buffone C, Giudice A. New therapeutic opportunities for COVID-19 patients with tocilizumab: possible correlation of interleukin- 6 receptor inhibitors with osteonecrosis of the jaws. Oral Oncol. 2020; 106:104659.

https://doi.org/10.1016/j.oraloncology.2020.104659 PMID: $\underline{2209313}$

9. Yang X, Yu Y, Xu J, Shu H, Xia J, Liu H, Wu Y, Zhang L, Yu $Z$, Fang $M, Y u T$, Wang $Y$, Pan $S$, et al. Clinical course and outcomes of critically ill patients with SARS-CoV-2 pneumonia in Wuhan, China: a single-centered, retrospective, observational study. Lancet Respir Med. 2020; 8:475-81.

https://doi.org/10.1016/S2213-2600(20)30079-5 PMID: $\underline{2105632}$

10. Lu CC, Chen MY, Lee WS, Chang YL. Potential therapeutic agents against COVID-19: what we know so far. J Chin Med Assoc. 2020; 83:534-36. https://doi.org/10.1097/JCMA.0000000000000318 PMID:32243270

11. Li $Y$, Chen $M$, Cao $H$, Zhu $Y$, Zheng J, Zhou $H$. Extraordinary GU-rich single-strand RNA identified from SARS coronavirus contributes an excessive innate immune response. Microbes Infect. 2013; 15:88-95. https://doi.org/10.1016/j.micinf.2012.10.008 PMID:23123977

12. Mahallawi WH, Khabour OF, Zhang Q, Makhdoum HM, Suliman BA. MERS-CoV infection in humans is associated with a pro-inflammatory Th1 and Th17 cytokine profile. Cytokine. 2018; 104:8-13.

https://doi.org/10.1016/i.cyto.2018.01.025 PMID:29414327

13. Wong CK, Lam CW, Wu AK, Ip WK, Lee NL, Chan IH, Lit LC, Hui DS, Chan MH, Chung SS, Sung JJ. Plasma inflammatory cytokines and chemokines in severe acute respiratory syndrome. Clin Exp Immunol. 2004; 136:95-103.

https://doi.org/10.1111/j.1365-2249.2004.02415.x

PMID: $\underline{15030519}$ 
14. Qin C, Zhou L, Hu Z, Zhang S, Yang S, Tao Y, Xie C, Ma K, Shang K, Wang W, Tian DS. Dysregulation of immune response in patients with coronavirus 2019 (COVID-19) in Wuhan, China. Clin Infect Dis. 2020; 71:762-68.

https://doi.org/10.1093/cid/ciaa248

PMID:32161940

15. Lau SK, Lau CC, Chan KH, Li CP, Chen H, Jin DY, Chan JF, Woo PC, Yuen KY. Delayed induction of proinflammatory cytokines and suppression of innate antiviral response by the novel Middle East respiratory syndrome coronavirus: implications for pathogenesis and treatment. J Gen Virol. 2013; 94:2679-90.

https://doi.org/10.1099/vir.0.055533-0

PMID:24077366

16. Zhang C, Wu Z, Li JW, Zhao H, Wang GQ. Cytokine release syndrome in severe COVID-19: interleukin-6 receptor antagonist tocilizumab may be the key to reduce mortality. Int J Antimicrob Agents. 2020; 55:105954.

https://doi.org/10.1016/j.ijantimicag.2020.105954 PMID: 32234467

17. Scheller J, Rose-John S. Interleukin-6 and its receptor: from bench to bedside. Med Microbiol Immunol. 2006; 195:173-83.

https://doi.org/10.1007/s00430-006-0019-9

PMID: 16741736

18. Nishimoto N, Kishimoto T, Yoshizaki K. Anti-interleukin 6 receptor antibody treatment in rheumatic disease. Ann Rheum Dis. 2000 (Suppl 1); 59:i21-27. https://doi.org/10.1136/ard.59.suppl 1.i21 PMID:11053081

19. Gabay C, Emery P, van Vollenhoven R, Dikranian A, Alten R, Pavelka K, Klearman M, Musselman D, Agarwal S, Green J, Kavanaugh A, and ADACTA Study Investigators. Tocilizumab monotherapy versus adalimumab monotherapy for treatment of rheumatoid arthritis (ADACTA): a randomised, double-blind, controlled phase 4 trial. Lancet. 2013; 381:1541-50.

https://doi.org/10.1016/S0140-6736(13)60250-0

PMID:23515142

20. Kaly L, Rosner I. Tocilizumab - a novel therapy for nonorgan-specific autoimmune diseases. Best Pract Res Clin Rheumatol. 2012; 26:157-65.

https://doi.org/10.1016/j.berh.2012.01.001

PMID:22424201

21. Yokota S, Imagawa T, Mori M, Miyamae T, Aihara $\mathrm{Y}$, Takei S, Iwata N, Umebayashi H, Murata T, Miyoshi M, Tomiita M, Nishimoto N, Kishimoto T. Efficacy and safety of tocilizumab in patients with systemic-onset juvenile idiopathic arthritis: a randomised, doubleblind, placebo-controlled, withdrawal phase III trial. Lancet. 2008; 371:998-1006.

https://doi.org/10.1016/S0140-6736(08)60454-7
PMID:18358927

22. Li YC, Bai WZ, Hashikawa T. The neuroinvasive potential of SARS-CoV2 may play a role in the respiratory failure of COVID-19 patients. J Med Virol. 2020; 92:552-55. https://doi.org/10.1002/jmv.25728 PMID:32104915

23. Chen Y, Liu Q, Guo D. Emerging coronaviruses: genome structure, replication, and pathogenesis. J Med Virol. 2020; 92:418-23.

https://doi.org/10.1002/jmv.25681 PMID:31967327

24. Su S, Wong G, Shi W, Liu J, Lai AC, Zhou J, Liu W, Bi Y, Gao GF. Epidemiology, genetic recombination, and pathogenesis of coronaviruses. Trends Microbiol. 2016; 24:490-502.

https://doi.org/10.1016/j.tim.2016.03.003

PMID:27012512

25. Wu Z, McGoogan JM. Characteristics of and important lessons from the coronavirus disease 2019 (COVID-19) outbreak in China: summary of a report of 72314 cases from the Chinese center for disease control and prevention. JAMA. 2020. [Epub ahead of print].

https://doi.org/10.1001/jama.2020.2648

PMID:32091533

26. Luo P, Liu Y, Qiu L, Liu X, Liu D, Li J. Tocilizumab treatment in COVID-19: a single center experience. J Med Virol. 2020; 92:814-18.

https://doi.org/10.1002/imv.25801

PMID:32253759

27. Nishimoto N, Terao K, Mima T, Nakahara H, Takagi N, Kakehi T. Mechanisms and pathologic significances in increase in serum interleukin-6 (IL-6) and soluble IL-6 receptor after administration of an anti-IL-6 receptor antibody, tocilizumab, in patients with rheumatoid arthritis and castleman disease. Blood. 2008; 112:3959-64.

https://doi.org/10.1182/blood-2008-05-155846 PMID:18784373

28. Ansar W, Ghosh S. C-reactive protein and the biology of disease. Immunol Res. 2013; 56:131-42.

https://doi.org/10.1007/s12026-013-8384-0 PMID:23371836

29. Han H, Ma Q, Li C, Liu R, Zhao L, Wang W, Zhang P, Liu X, Gao G, Liu F, Jiang Y, Cheng X, Zhu C, Xia Y. Profiling serum cytokines in COVID-19 patients reveals IL-6 and IL-10 are disease severity predictors. Emerg Microbes Infect. 2020; 9:1123-30. https://doi.org/10.1080/22221751.2020.1770129 PMID: $\underline{32475230}$

30. Pedersen SF, Ho YC. SARS-CoV-2: a storm is raging. J Clin Invest. 2020; 130:2202-05.

https://doi.org/10.1172/JCl137647

PMID:르료 
31. Gu Y, Hsu AC, Pang Z, Pan H, Zuo X, Wang G, Zheng J, Wang $F$. Role of the Innate Cytokine Storm Induced by the Influenza A Virus. Viral Immunol. 2019; 32:244-251. https://doi.org/10.1089/vim.2019.0032 PMID:31188076

32. (NHC), C.N.H.C., Chinese management guideline for COVID-19 (version 7.0). Feb 2020 p

33. Korniluk A, Koper-Lenkiewicz OM, Kamińska J, Kemona $\mathrm{H}$, Dymicka-Piekarska V. Mean platelet volume (MPV): new perspectives for an old marker in the course and prognosis of inflammatory conditions. Mediators Inflamm. 2019; 2019:9213074.

https://doi.org/10.1155/2019/9213074

PMID:31148950

34. Tamer F, Yuksel ME, Avcı E. Is mean platelet volume an inflammatory marker in acne patients treated with isotretinoin? Acta Dermatovenerol Alp Pannonica Adriat. 2019; 28:65-69.

https://doi.org/10.15570/actaapa.2019.17 PMID:31233169

35. Wang X, Meng H, Xu L, Chen Z, Shi D, Lv D. Mean platelet volume as an inflammatory marker in patients with severe periodontitis. Platelets. 2015; 26:67-71. https://doi.org/10.3109/09537104.2013.875137 PMID:24499137

36. Pepys MB, Hirschfield GM. C-reactive protein: a critical update. J Clin Invest. 2003; 111:1805-12.
https://doi.org/10.1172/JCl18921

PMID:12813013

37. Hahn WH, Song JH, Kim H, Park S. Is procalcitonin to creactive protein ratio useful for the detection of late onset neonatal sepsis? J Matern Fetal Neonatal Med. 2018; 31:822-26.

https://doi.org/10.1080/14767058.2017.1297410

PMID:28277917

38. Mooiweer E, Luijk B, Bonten MJ, Ekkelenkamp MB. Creactive protein levels but not CRP dynamics predict mortality in patients with pneumococcal pneumonia. J Infect. 2011; 62:314-16.

https://doi.org/10.1016/j.jinf.2011.01.012

PMID:21281676

39. Liu F, Li L, Xu M, Wu J, Luo D, Zhu Y, Li B, Song X, Zhou $X$. Prognostic value of interleukin-6, c-reactive protein, and procalcitonin in patients with COVID-19. J Clin Virol. 2020; 127:104370.

https://doi.org/10.1016/j.jcv.2020.104370

PMID: $\underline{32344321}$ 